\title{
AURKA, DLGAP5, TPX2, KIF11 and CKAP5: Five specific mitosis-associated genes correlate with poor prognosis for non-small cell lung cancer patients
}

\author{
MARC A. SCHNEIDER ${ }^{1,8}$, PETROS CHRISTOPOULOS ${ }^{2,8}$, THOMAS MULEY ${ }^{1,8}$, \\ ARNE WARTH $^{5,8}$, URSULA KLINGMUELLER ${ }^{6,8,9}$, MICHAEL THOMAS ${ }^{2,8}$, FELIX J.F. HERTH ${ }^{3,8}$, \\ HENDRIK DIENEMANN $^{4,8}$, NIKOLA S. MUELLER ${ }^{7,9}$, FABIAN THEIS $^{7,9}$ and MICHAEL MEISTER ${ }^{1,8,9}$ \\ ${ }^{1}$ Translational Research Unit, ${ }^{2}$ Department of Thoracic Oncology, ${ }^{3}$ Department of Pneumology and Critical \\ Care Medicine, and ${ }^{4}$ Department of Surgery, Thoraxklinik at University Hospital Heidelberg, Heidelberg; \\ ${ }^{5}$ Institute of Pathology, University of Heidelberg, Heidelberg; ${ }^{6}$ Systems Biology of Signal Transduction, \\ German Cancer Research Center, Heidelberg; ${ }^{7}$ Cellular Dynamics and Cell Patterning, Max Planck Institute of \\ Biochemistry, Martinsried; ${ }^{8}$ Translational Lung Research Center Heidelberg (TLRC-H), Member of the German \\ Center for Lung Research (DZL) Heidelberg; ${ }^{9}$ CancerSys network 'LungSysII', Heidelberg, Germany
}

Received October 26, 2016; Accepted December 5, 2016

DOI: $10.3892 /$ ijo.2017.3834

\begin{abstract}
The growth of a tumor depends to a certain extent on an increase in mitotic events. Key steps during mitosis are the regulated assembly of the spindle apparatus and the separation of the sister chromatids. The microtubule-associated protein Aurora kinase A phosphorylates DLGAP5 in order to correctly segregate the chromatids. Its activity and recruitment to the spindle apparatus is regulated by TPX2. KIF11 and CKAP5 control the correct arrangement of the microtubules and prevent their degradation. In the present study, we investigated the role of these five molecules in non-small cell lung cancer (NSCLC). We analyzed the expression of the five genes in a large cohort of NSCLC patients $(n=362)$ by quantitative real-time PCR. Each of the genes was highly overexpressed in the tumor tissues compared to corresponding normal lung tissue. The correlation of the expression of the individual genes depended on the histology. An increased expression of AURKA, DLGAP5, TPX2, KIF11 and CKAP5 was associated with poor overall survival $(\mathrm{P}=0.001-0.065)$. AURKA was a significant prognostic marker using multivariate analyses $(\mathrm{P}=0.006)$. Immunofluorescence studies demonstrated that the five mitosis-associated proteins co-localized with the spindle apparatus during cell division. Taken together, our data demonstrate that the expression of the mitosis-associated
\end{abstract}

Correspondence to: Dr Marc A. Schneider, Translational Research Unit, Thoraxklinik at University Hospital Heidelberg, Roentgenstrasse 1, D-69126 Heidelberg, Germany

E-mail: marc.schneider@med.uni-heidelberg.de

Key words: mitosis, non-small cell lung cancer, gene expression, prognostic marker genes AURKA, DLGAP5, TPX2, KIF11 and CKAP5 is associated with the prognosis of NSCLC patients.

\section{Introduction}

Lung cancer is globally the leading cause of cancer-related deaths (1). Non-small cell lung cancer(NSCLC), which accounts for more than $80 \%$ of all cases, is divided in adenocarcinoma (ADC), squamous cell carcinoma (SCC) and large cell carcinoma (LCLC). The 5-year survival rate of lung cancer with $15 \%$ is still poor (2). A deregulated gene and protein expression of mitosis associated factors to force chromosomal segregation during the cell division is frequently observed in cancer. The analysis of the molecular landscape revealed a high mutation rate of cell cycle genes in ADC (64\%) (3). Furthermore, it was shown that the proliferation rate of NSCLC is predictive for the survival of the patients (4). A high expression of Ki-67 resulted in a poor prognosis in patients with ADC while it was associated with better prognosis in SCC patients (5). Cell cycle associated proteins including components that contribute to the execution of mitosis are indispensable for the proliferation of tumor cells. During mitosis, the kinetochore properly attaches to the chromosomes in microtubules to ensure correct segregation (6). The formation of the bipolar spindle and the segregation process are coordinated by the Aurora A kinase (AURKA) (7). AURKA promotes the entry into mitosis under the control of cyclin $\mathrm{B} / \mathrm{CDK} 1$ and regulates the progression of mitosis by phosphorylation of multiple targets (8-10). Several cofactors influence the activity of the AURKA during this process. The targeting protein for Xklp2 (TPX2) is one of these AURKA cofactors. During mitosis, TPX2 activity is controlled by the importin $\alpha / \beta$-Ran system (11). TPX2 causes AURKA to adopt an active conformation and protects it from dephosphorylation (12). A direct target that is phosphorylated by the AURKA is the disks large-associated protein 5 
(DLGAP5) (13). DLGAP5 is a mitotic spindle protein that promotes the formation of tubulin polymers resulting in tubulin sheets around the end of the microtubules (14). The association of DLGAP5 with the mitotic spindle is stabilized through the phosphorylation by AURKA (15). The kinesin family member 11 (KIF11) is a motor protein of the kinesin-5-family which cross-links antiparallel microtubules in the spindle (16). Its movement is regulated by TPX2 binding (17). The cytoskeleton associated protein 5 (CKAP5) protects the kinetochore microtubules from depolymerization and plays a role in the assembly of central microtubules $(18,19)$. A protein complex named EXATH (comprising AURKA, TPX2 and DLGAP5, KIF11 and CKAP5) which was described in Xenopus egg extract, was shown to exhibit MT-stabilizing and organizing activities, and to contribute to the maturation and formation of the mitotic spindle (20). Current studies primarily targeted AURKA. In vitro studies with NSCLC cell lines indicated that the AURKA inhibitor MK-5108 promises to be a potent drug in combination with docetaxel (21). However, clinical trials with the AURKA inhibitors VX-680 and AT9283 had to be terminated because of severe toxicities in patients with chronic myelogenous leukemia (22). Furthermore, the AURKA inhibitor alisertib displayed a response rate of only $9 \%$ in a phase I/II study (23). A knockdown of KIF11 with siRNA as well as its inhibition with ispinesib resulted in a strong decrease of the viability of NSCLC cells (24). Therefore, we investigated in this study the expression of AURKA, DLGAP5, TPX2, KIF11 and CKAP5 in a large cohort of adeno- and squamous cell carcinoma patients $(n=362)$ to evaluate their prognostic significance and the potential as therapeutic targets for NSCLC.

\section{Materials and methods}

Tissue sample collection, characterization and preparation. Tissue samples were provided by the Lung Biobank Heidelberg, a member of the accredited Tissue Bank of the National Center for Tumor Diseases (NCT) Heidelberg, the BioMaterialBank Heidelberg, and the Biobank platform of the German Center for Lung Research (DZL). Tumor and matched distant $(>5 \mathrm{~cm})$ normal lung tissue samples from NSCLC patients $(n=362)$ who underwent resection for primary lung cancer at the Thoraxklinik at University Hospital, Heidelberg, Germany, were collected. All diagnoses were made according to the 2004 WHO classification for lung cancer by at least two experienced pathologists (25). Tumor stage was designated according to the 7th edition of the UICC tumor, node and metastasis (26). Tissues were snap-frozen within $30 \mathrm{~min}$ after resection and stored at $-80^{\circ} \mathrm{C}$ until the time of analysis. For nucleic acid isolation 10-15 tumor cryosections (10-15 $\mu \mathrm{m}$ each) were prepared for each patient. The first and the last sections in each series were stained with hematoxylin and eosin (H\&E) and were reviewed by an experienced lung pathologist to determine the proportions of viable tumor cells, stromal cells, normal lung cell cells, infiltrating lymphocytes and necrotic areas. Only samples with a viable tumor content of $\geq 50 \%$ were used for subsequent analyses.

Total RNA isolation and cDNA synthesis. Total RNA was isolated from tissue using an RNeasy Mini kit (Qiagen, Hilden, Germany) according to the manufacturer's instructions. For
RNA isolation from cell lines, the AllPrep DNA/RNA Mini kit (Qiagen) was used. Total RNA was transcribed to sscDNA with a Transcriptor First Strand cDNA Synthesis kit (Roche Diagnostics GmbH, Mannheim, Germany). More detailed information is described elsewhere (27).

Quantitative real-time PCR ( $q P C R$ ). Real-time quantitative PCR (qPCR) was performed in accordance with the MIQEguidelines (28) using a LightCycler ${ }^{\circledR} 480$ real-time PCR instrument in a 384-well plate format (Roche Diagnostics). Gene-specific primers and probes (Universal ProbeLibrary; Roche Diagnostics) were used in combination with the ABsolute $^{\mathrm{TM}}$ qPCR Mix (Fisher Scientific GmbH, Schwerte, Germany). CT values were calculated with the LightCycler ${ }^{\circledR}$ 480 software version 1.5 using the 2 nd derivative maximum method (Roche Diagnostics). Detailed information is described elsewhere (27).

Statistical analyses. Data of qPCR analyses were statistically analyzed using REMARK criteria (29) with the SPSS 22.0 for Windows (IBM, Ehningen, Germany). The primary endpoint of the study was overall survival. Overall survival time was calculated from the date of surgery until the last date of contact or death. Univariate analysis of survival data was performed according to Kaplan-Meier (30) and using the Cox proportional hazards model. The log-rank test was used to test the significance between the groups. A P-value of $<0.05$ was considered significant. Multivariate survival analysis was performed using the Cox proportional hazards model. The non-parametric MannWhitney U test (31) as well as the Kruskal-Wallis test (32) were used to investigate significant differences between the patient groups. The Spearman's rank correlation coefficient test was performed for correlation analyses (33). Visualization of the qPCR data was performed using the GraphPad Prism 5.

Cell culture. H838 and H1975 cell lines were purchased from the American Type Culture Collection (ATCC; Wesel, Germany) and cultivated in DMEM/Ham's F-12 (Life Technologies, Darmstadt, Germany) with $10 \%$ fetal calf serum (FCS; GE Healthcare Life Sciences, Freiburg, Germany) for not more than 20 passages. H838 cell line was cultivated in RPMI-1640 (Life Technologies) with 10\% FCS.

Immunofluorescence analyses (IF) and immunohistochemistry (IHC). For IF, $1.5 \times 10^{5} \mathrm{H} 1975$ or $2 \times 10^{5} \mathrm{H} 838$ were seeded onto a 12 -well plate. The next day, cells were fixed with ice cold methanol for $10 \mathrm{~min}$ at $-20^{\circ} \mathrm{C}$ and incubated with the indicated antibodies overnight at $4^{\circ} \mathrm{C}$. Anti-AURKA (\#4718; Cell Signaling Technology, Danvers, MA, USA), anti-TPX2 (NB500-179; Acris Antibodies GmbH, Herford, Germany), anti-DLGAP5 (sc-68540; Santa Cruz Biotechnology, Heidelberg, Germany), anti-KIF11 (sc-365681; Santa Cruz Biotechnology) and anti-CKAP5 (sc-240235; Santa Cruz Biotechnology) antibodies were used to stain the spindle associated proteins. Cells were incubated with secondary antibodies (Alexa Fluor dyes; Dianova GmbH, Hamburg, Germany) for $40 \mathrm{~min}$ at $37^{\circ} \mathrm{C}$. Hoechst 33342 (Sigma-Aldrich, Munich, Germany) was used for nuclear staining. Cells were covered with coverslips using Fluoprep (75521; Biomérieux Deutschland GmbH, Nuertingen, Germany). 

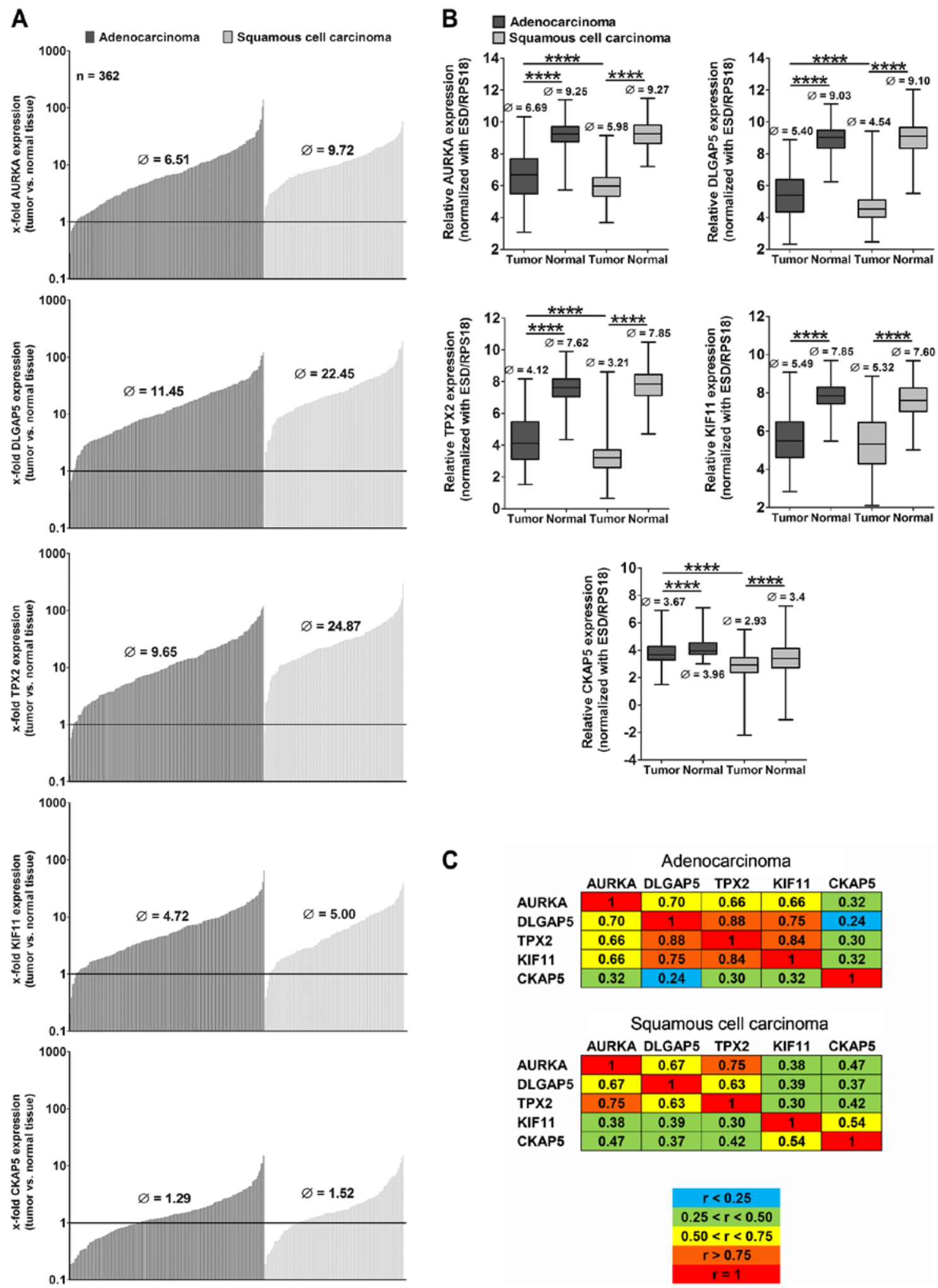

C

\begin{tabular}{l|c|c|c|c|c|}
\multicolumn{7}{c}{ Adenocarcinoma } \\
\multicolumn{1}{c}{ AURKA } & DLGAP5 & \multicolumn{1}{c}{ TPX2 } & \multicolumn{1}{c}{ KIF11 } & \multicolumn{1}{c}{ CKAP5 } \\
AURKA & 1 & 0.70 & 0.66 & 0.66 & 0.32 \\
\cline { 2 - 6 } DLGAP5 & 0.70 & 1 & 0.88 & 0.75 & 0.24 \\
\cline { 2 - 6 } TPX2 & 0.66 & 0.88 & 1 & 0.84 & 0.30 \\
\cline { 2 - 6 } KIF11 & 0.66 & 0.75 & 0.84 & 1 & 0.32 \\
\cline { 2 - 6 } CKAP5 & 0.32 & 0.24 & 0.30 & 0.32 & 1
\end{tabular}

\begin{tabular}{|c|c|c|c|c|c|}
\hline & \multicolumn{5}{|c|}{ Squamous cell carcinoma } \\
\hline & AURKA & DLGAP5 & TPX2 & KIF11 & CKAP5 \\
\hline AURKA & 1 & 0.67 & 0.75 & 0.38 & 0.47 \\
\hline DLGAP5 & 0.67 & 1 & 0.63 & 0.39 & 0.37 \\
\hline TPX2 & 0.75 & 0.63 & 1 & 0.30 & 0.42 \\
\hline KIF11 & 0.38 & 0.39 & 0.30 & 1 & 0.54 \\
\hline CKAP5 & 0.47 & 0.37 & 0.42 & 0.54 & 7 \\
\hline
\end{tabular}

Figure 1. Gene expression profile of five mitotic spindle proteins in NSCLC patients. (A) Waterfall plots with $\mathrm{x}$-fold gene expression (tumor vs. normal tissue) of 362 NSCLC patients. (B) Comparison of relative gene expression in tumor and normal tissue after normalization. Please note that lower Ct-values indicate a higher gene expression. Boxes indicate $25-75 \%$ of the population and the median. (C) Correlation analyzes of AURKA, DLGAP5, TPX2, KIF11 and CKAP5 expression in the NSCLC subtypes ADC and SCC. ${ }^{* * * *} \mathrm{P}<0.001$.

Pictures were taken with an Olympus IX71 inverted microscope. Staining was observed with Olympus ColorView II digital camera and with the Olympus cellSens software (Olympus). Tiffs were assembled into figures using Photoshop CS6 (Adobe Photoshop).

\section{Results}

AURKA, DLGAP5, TPX2, KIF11 and CKAP5 are highly overexpressed in NSCLC. To investigate the role of the above five mitosis-associated genes in NSCLC, we analyzed the 
Table I. Patient characteristics.

\begin{tabular}{|c|c|}
\hline \multirow[b]{2}{*}{ Parameters } & \multirow{2}{*}{$\frac{\text { Gene expression analyses }}{\mathrm{n}(\%)}$} \\
\hline & \\
\hline Median age (years) & $65(38-88)$ \\
\hline Gender & 362 \\
\hline Male & $250(69)$ \\
\hline Female & $112(31)$ \\
\hline \multicolumn{2}{|l|}{ Histology } \\
\hline Adenocarcinoma & $211(58)$ \\
\hline Squamous cell carcinoma & $151(42)$ \\
\hline \multicolumn{2}{|l|}{ Therapy } \\
\hline OP & $212(59)$ \\
\hline $\mathrm{OP} / \mathrm{RT}$ & $13(4)$ \\
\hline $\mathrm{OP} / \mathrm{CT}$ & $100(28)$ \\
\hline OP/RT/CT & $37(10)$ \\
\hline \multicolumn{2}{|l|}{ P-stage } \\
\hline IA & $37(10)$ \\
\hline IB & $90(25)$ \\
\hline IIA & $70(19)$ \\
\hline IIB & $51(14)$ \\
\hline IIIA & $105(29)$ \\
\hline IIIB & $9(2)$ \\
\hline \multicolumn{2}{|l|}{ ECOG } \\
\hline 0 & $320(88)$ \\
\hline 1 & $32(9)$ \\
\hline 2 & $4(1)$ \\
\hline n.d. & $8(2)$ \\
\hline
\end{tabular}

OP, surgery; CT, chemotherapy; RT, radiotherapy; ECOG, Eastern Cooperative Oncology Group; n.d., no data. tissue $(n=362)$ of patients who underwent surgery (Table I) by qPCR. AURKA, DLGAP5, TPX2, KIF11 were highly overexpressed in $>96 \%$ of all tumors compared to normal lung tissue, CKAP5 was overexpressed in $\sim 70 \%$ of the patients, but to a lower level than the other four genes (Fig. 1A). In general, the overexpression of the genes was much higher in squamous cell carcinomas (SCC) compared to adenocarcinomas (ADC) and differed significantly from gene expression in normal tissue (Fig. 1B). In SCC we observed a higher expression in advanced stages compared to stage I with the exception of KIF11 which was lower expressed in stage III compared to stage I (data not shown). No significant differences were observed in the gene expression of tumors between males and females (data not shown). Since the five proteins were described to interact and to form a complex during cell mitosis (20), we were interested whether we could find any correlation between the expression of the genes. The correlation of the expression of the genes differed with respect to the different histologies (Fig. 1C). In ADC, AURKA, DLGAP5, TPX2 and KIF11 all showed correlation values $r>0.66$. Only CKAP5 expression did not exhibit
Table II. Statistical analyses (Cox-regression) of relative tumor expression.

\begin{tabular}{lcc}
\hline Variables & $\begin{array}{c}\text { Hazard ratio } \\
(95 \% \text { CI })\end{array}$ & P-value \\
\hline Univariate analyses of disease-free survival & \\
AURKA (high vs. low) & $2.813(1.656-4.779)$ & $<\mathbf{0 . 0 0 1}$ \\
DLGAP5 & $1.669(1.223-2.276)$ & $\mathbf{0 . 0 0 1}$ \\
TPX2 & $1.826(1.167-2.857)$ & $\mathbf{0 . 0 0 7}$ \\
KIF11 & $1.891(0.966-3.705)$ & 0.063 \\
CKAP5 & $1.364(0.998-1.865)$ & $\mathbf{0 . 0 5}$
\end{tabular}

Multivariate analyses of disease-free survival

$\begin{array}{lrr}\text { AURKA (high vs. low) } & 2.486(1.298-4.761) & \mathbf{0 . 0 0 6} \\ \text { DLGAP5 } & 1.338(0.928-1.928) & 0.119 \\ \text { TPX2 } & 0.86(0.475-1.555) & 0.617 \\ \text { CKAP5 } & 1.141(0.815-1.598) & 0.441 \\ \text { Histology (SCC vs. ADC) } & 0.642(0.455-0.906) & \mathbf{0 . 0 1 2} \\ \text { Gender (male vs. female) } & 1.216(0.858-1.723) & 0.272 \\ \text { pStage (II vs. I) } & 1.468(0.968-2.226) & 0.071 \\ \text { pStage (III vs. I) } & 2.562(1.715-3.829) & <\mathbf{0 . 0 0 1} \\ \text { Age } & 1.018(1.001-1.036) & \mathbf{0 . 0 3 4}\end{array}$

Univariate analyses of disease-free survival in ADC

AURKA (high vs. low) $\quad 3.498$ (1.985-6.164)

DLGAP5

$2.011(1.356-2.984)$

$<0.001$

TPX2

$2.226(1.374-3.605)$

$<0.001$

KIF11

$2.855(1.246-6.541)$

0.001

CKAP5

$1.533(1.031-2.279)$

0.013

0.033

Univariate analyses of disease-free survival in SCC

$\begin{array}{lll}\text { AURKA (high vs. low) } & 0.753(0.104-5.435) & 0.777 \\ \text { DLGAP5 } & 1.293(0.591-2.827) & 0.519 \\ \text { TPX2 } & 1.368(0.68-2.750) & 0.377 \\ \text { KIF11 } & 1.460(0.904-2.357) & 0.12 \\ \text { CKAP5 } & 0.735(0.403-1.338) & 0.312\end{array}$

CI, confidence interval; ADC, adenocarcinoma; SCC, squamous cell carcinoma.

significant associations with the other genes. In SCC, CKAP5 slightly correlated with KIF11 ( $\mathrm{r}=0.54)$ but only AURKA and TPX2 displayed a high correlation in the tumor tissue $(r=0.75)$.

AURKA, DLGAP5, TPX2, KIF11 and CKAP5 are factors for poor disease-free survival in NSCLC patients. In survival analyses, we studied the association between the increased gene expression and the survival of the patients. We used the optimal cut-off value calculated by an R-based tool (34) to separate the groups with high and low gene expression in the tumor tissue. In univariate analyses we found significantly increased hazard ratios and poor disease-free survival in patients with a high gene expression of AURKA $(\mathrm{HR}=2.813$, $\mathrm{P} \leq 0.001)$, DLGAP5 $(\mathrm{HR}=1.669, \mathrm{P}=0.001)$, TPX2 $(\mathrm{HR}=1.826$, $\mathrm{P}=0.007)$ and CKAP5 ( $\mathrm{P}=0.05)$ (Table II and Fig. 2). In multivariate analyses using clinical parameters and the AURKA 

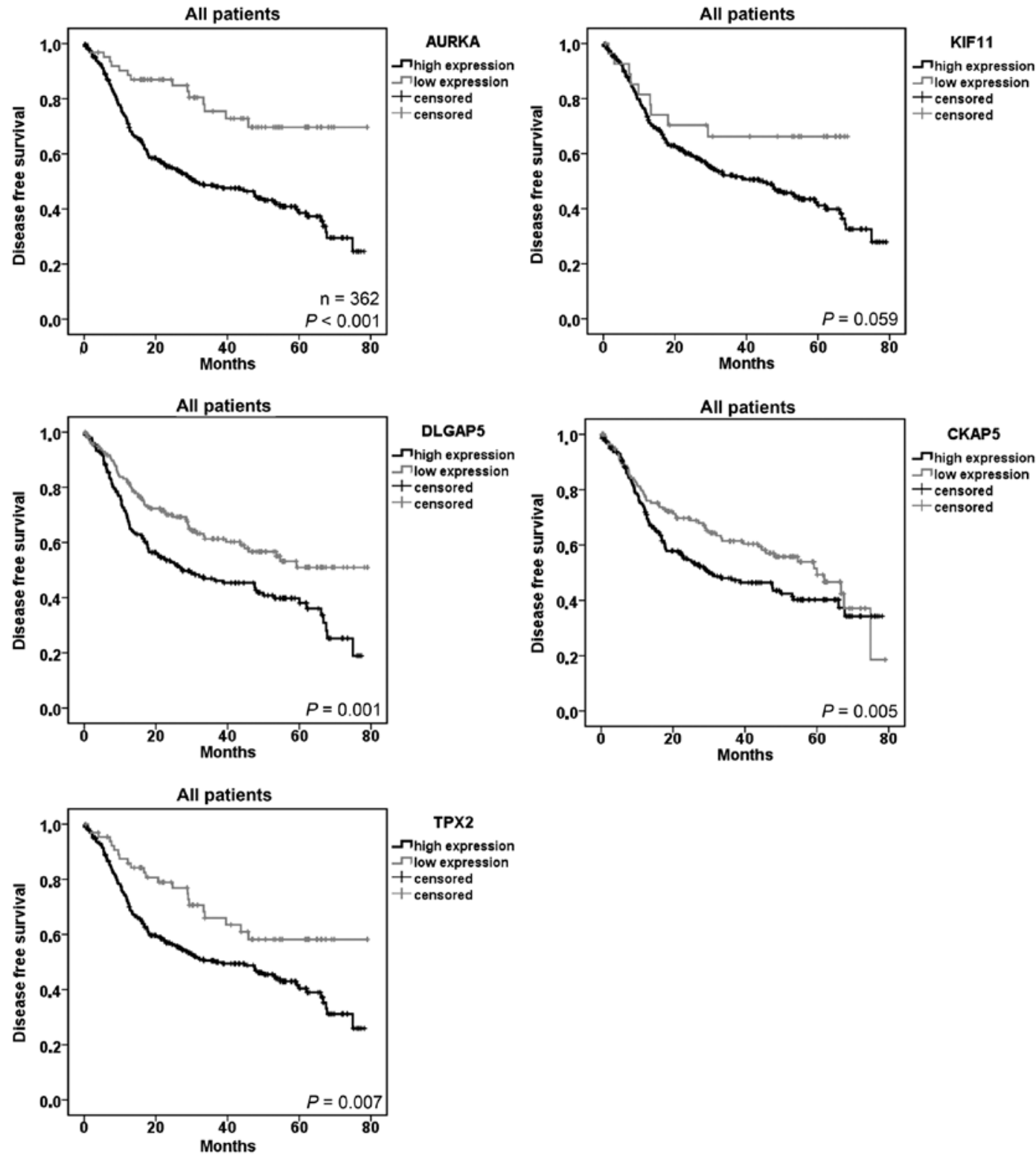

Figure 2. Survival analyses. Kaplan-Meier curves of patient disease-free survival according to the gene expression of AURKA, DLGAP5, TPX2, KIF11 and CKAP5.

expression, the histology, the pathological stage (III vs. I) as well as the age were prognostic factors for disease-free survival. Considering the subhistologies, a high gene expression of the five mitosis-associated genes resulted in a poor prognosis of patients with ADC, but not with SCC. KIF11 barely failed to be a prognostic marker in univariate analyses.

DLGAP5, KIF11 and CKAP5 co-localize with TPX2 and AURKA at the spindle apparatus during cell division. To clarify whether the five proteins might also form a complex in lung cancer cells, we performed immunofluorescence analyses and co-stainings of DLGAP5, KIF11 and CKAP5 with AURKA and TPX2 in the the lung cancer cell line H838 (Fig. 3). In non-dividing cells, AURKA, TPX2, DLGAP5 and CKAP5 were localized in the cytoplasm and the nucleus (Fig. 3, first two columns). In contrast, KIF11 was mainly expressed in the cytoplasm of the cells. In cells undergoing mitosis, DLGAP5, KIF11 and CKAP5 co-localized with AURKA and TPX2 at the spindle apparatus and the microtubules (last two columns). While the AURKA was mainly localized at the centrosomes (Fig. 3, rows 2, 4 and 6), DLGAP5, KIF11 and TPX2 covered the entire microtubules. CKAP5 exhibited a more distributed pattern and co-localized with AURKA and TPX2 only at the centrosomes (rows 5 and 6). Similar results were obtained for the cell line H1975 (data not shown).

\section{Discussion}

In the present study, we demonstrated that the five cell cycle associated genes AURKA, DLGAP5, TPX2, KIF11 and CKAP5 were overexpressed in NSCLC tumor tissue compared to corresponding adjacent non-neoplastic lung tissue. Especially AURKA, TPX2 and DLGAP5 were found to be highly upregulated and correlated with each other. It was shown that during the cell cycle TPX2 and DLGAP5 are phosphorylated by AURKA $(15,35)$. Therefore, a coexpression of 

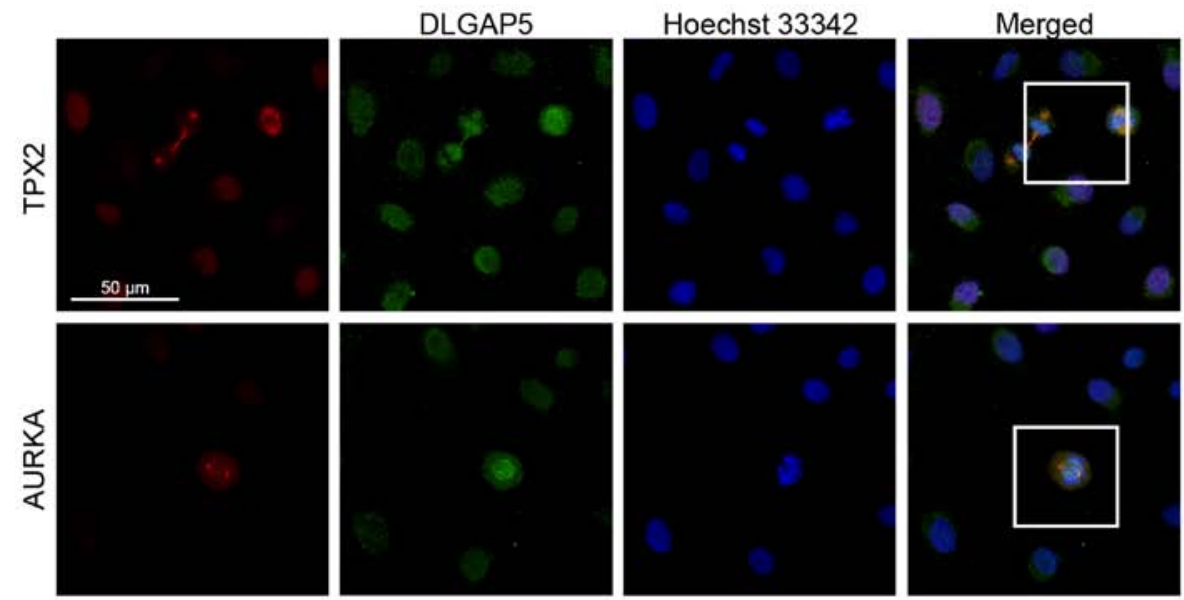

Enlarged
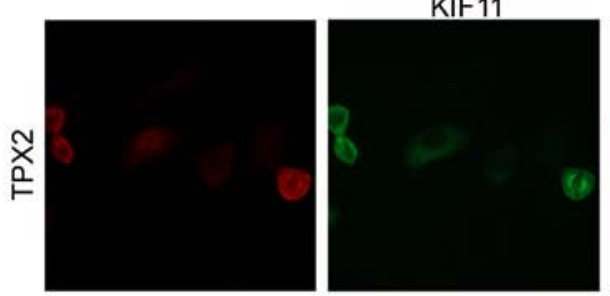

Hoechst 33342
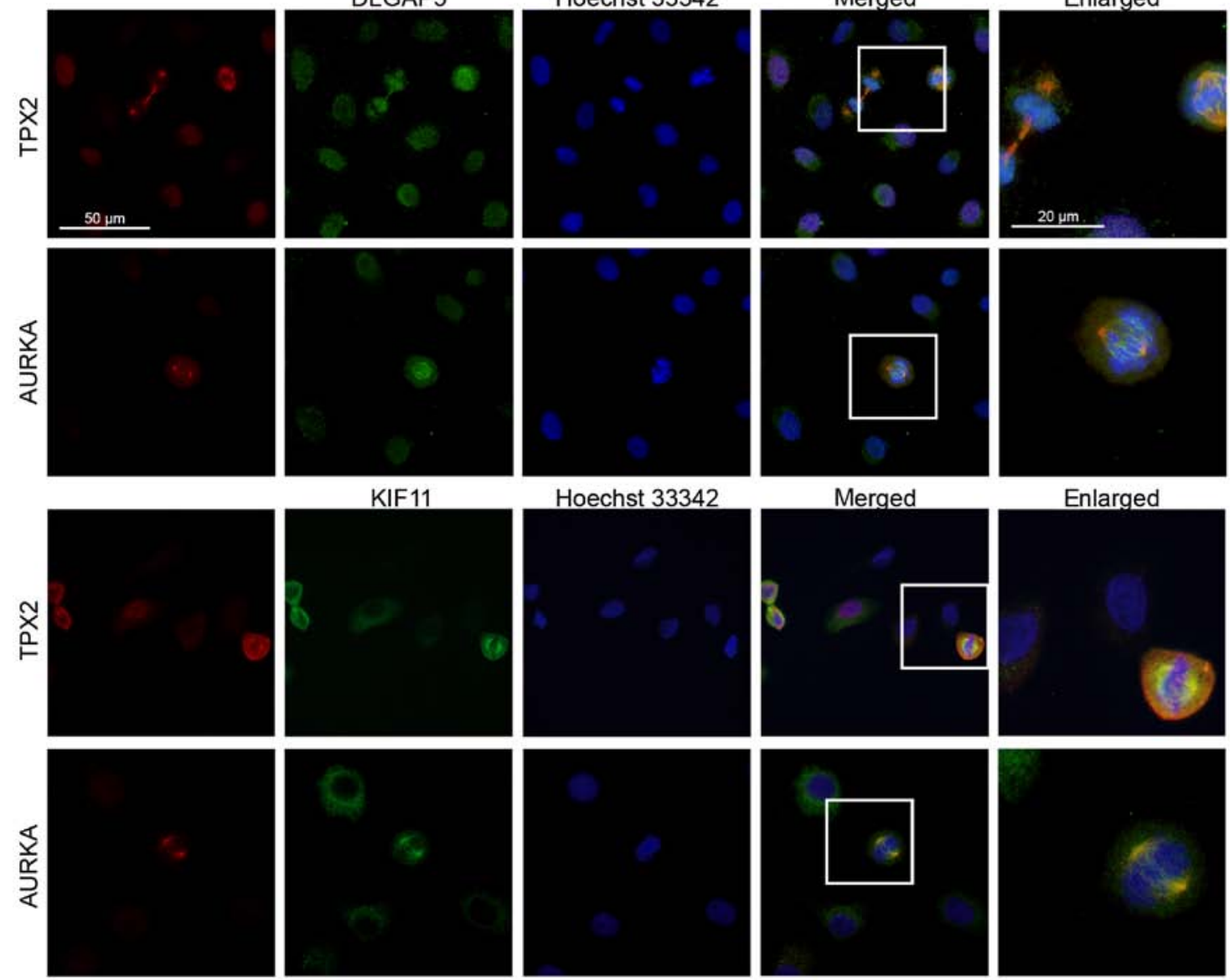

CKAP5
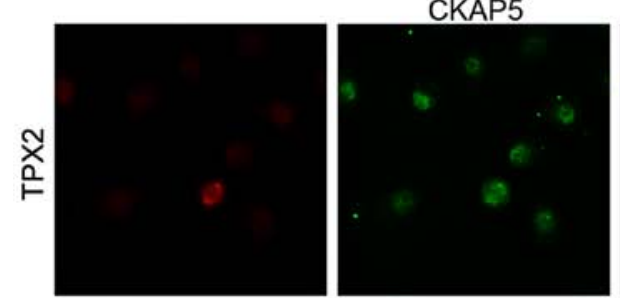

Hoechst 33342
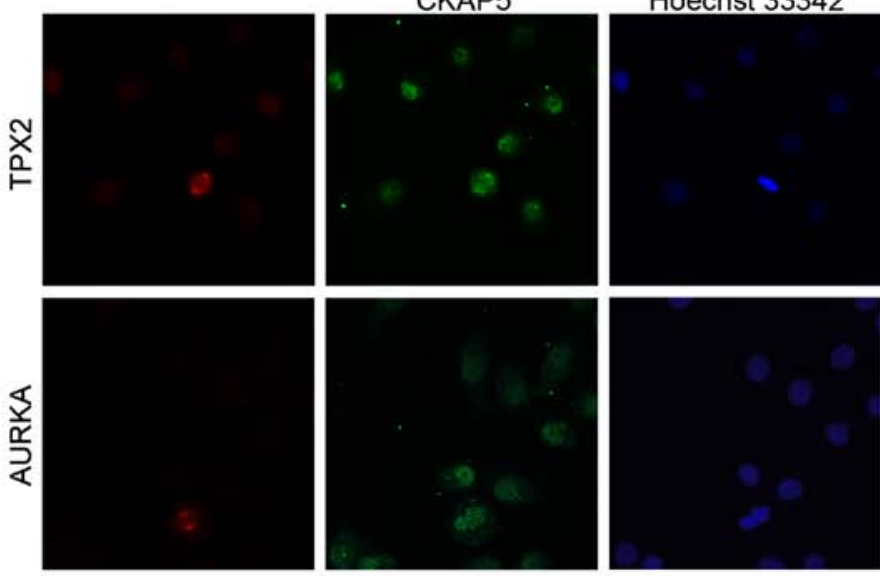

Merged
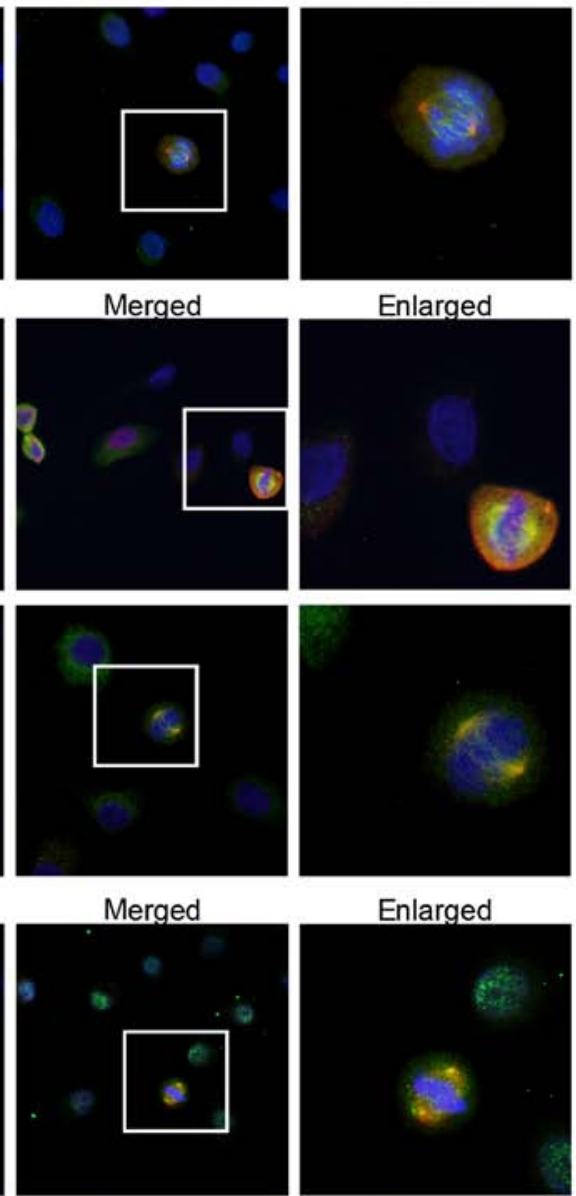

Enlarged
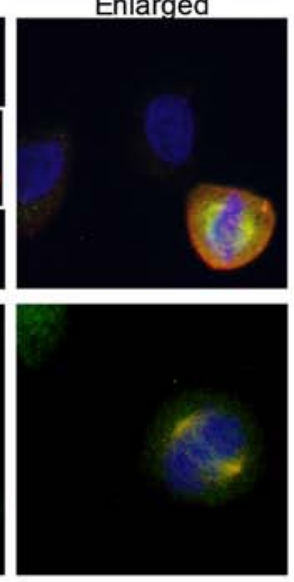

Enlarged
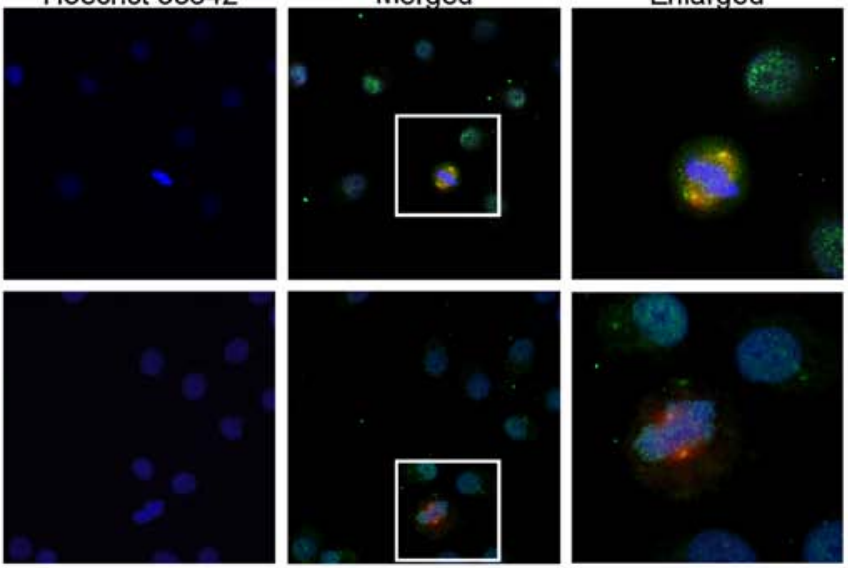

Figure 3. Colocalization studies. Co-immunofluorescence analyses of DLGAP5, KIF11 and CKAP5 with AURKA and TPX2 in H838 cells. Representative pictures of dividing cells were selected.

AURKA with TPX2 and DLGAP5 seems reasonable. While KIF11 correlated with these three genes in ADC, this was not the case in SCC. CKAP5 did not correlate with the expression of any of the other genes. The five investigated proteins were shown to form a complex in Xenopus egg extract (20). Here, the survival analyses of the qPCR expression data indicated that for NSCLC this complex might only be prognostically relevant for patients with ADC. Furthermore, AURKA was the only gene which was prognostic for the disease-free survival in multivariate analysis. This is in agreement with the cellular role of AURKA since it was demonstrated that AURKA phosphorylates important cell cycle proteins including DLGAP5 $(13,22)$.
With immunofluorescence analyses, we demonstrated that the proteins DLGAP5 and KIF11 co-localized with AURKA and TPX 2 in lung cancer cells during cell mitosis. The expression pattern of CKAP5 correlated only partly with the expression pattern of AURKA and TPX2. Neither in ADC nor SCC a correlation between CKAP5 and the other two genes was observed.

With regard to the potential of the investigated genes as therapeutic targets for NSCLC, screening studies frequently discovered some of these genes to be essential for tumor survival in lung cancer $(24,36,37)$. A cell cycle progression score (CCP) including DLGAP5 and KIF11 was shown to be 
prognostic for different cancer entities $(38,39)$. Concerning lung cancer, this $\mathrm{CCP}$ was prognostic mainly for patients with ADC $(38,40)$. An extension of the score using TPX2 and AURKA might improve the prognostic value of the CCP score.

In conclusion, in the present study, we demonstrated for the first time the co-expression of DLGAP5, KIF11 and CKAP5 in NSCLC patients together with TPX2 and AURKA. All five genes were prognostic markers for the survival of the patients. For TPX2, DLGAP5 and CKAP5 so far no in vitro or in vivo studies concerning drug application have been described. Since our data indicated that there is a strong correlation between AURKA, TPX2 and DLGAP5 expression in NSCLC patients, these three genes might be particularly suitable targets for future therapeutic studies.

\section{Acknowledgements}

We would like to thank Chang Xu, Martin Fallenbuechel, Jessica Eschenbach, Carmen Hoppstock, Christa Stolp and Andrea Bopp for their expert technical assistance.

\section{References}

1 Ferlay J, Soerjomataram I, Dikshit R, Eser S, Mathers C, Rebelo M, Parkin DM, Forman D and Bray F: Cancer incidence and mortality worldwide: sources, methods and major patterns in GLOBOCAN 2012. Int J Cancer 136: E359-E386, 2015.

2. Youlden DR, Cramb SM and Baade PD: The International Epidemiology of Lung Cancer: geographical distribution and secular trends. J Thorac Oncol 3: 819-831, 2008.

3. Ding L, Getz G, Wheeler DA, Mardis ER, McLellan MD, Cibulskis K, Sougnez C, Greulich H, Muzny DM, Morgan MB, et al: Somatic mutations affect key pathways in lung adenocarcinoma. Nature 455: 1069-1075, 2008.

4. Sofocleous CT, Garg SK, Cohen P, Petre EN, Gonen M, Erinjeri JP, Downey RJ, Travis WD and Solomon SB: Ki-67 is an independent predictive biomarker of cancer specific and local recurrence-free survival after lung tumor ablation. Ann Surg Oncol 20 (Suppl 3): S676-S683, 2013.

5. Warth A, Cortis J, Soltermann A, Meister M, Budczies J, Stenzinger A, Goeppert B, Thomas M, Herth FJ, Schirmacher P, et al: Tumour cell proliferation (Ki-67) in non-small cell lung cancer: A critical reappraisal of its prognostic role. Br J Cancer 111: 1222-1229, 2014.

6. Pinsky BA and Biggins S: The spindle checkpoint: Tension versus attachment. Trends Cell Biol 15: 486-493, 2005.

7. Hannak E, Kirkham M, Hyman AA and Oegema K: Aurora-A kinase is required for centrosome maturation in Caenorhabditis elegans. J Cell Biol 155: 1109-1116, 2001.

8. Satinover DL, Brautigan DL and Stukenberg PT: Aurora-A kinase and inhibitor-2 regulate the cyclin threshold for mitotic entry in Xenopus early embryonic cell cycles. Cell Cycle 5: 2268-2274, 2006.

9. Macůrek L, Lindqvist A, Lim D, Lampson MA, Klompmaker R, Freire R, Clouin C, Taylor SS, Yaffe MB and Medema RH: Polo-like kinase-1 is activated by aurora A to promote checkpoint recovery. Nature 455: 119-123, 2008.

10. Mori D, Yano Y, Toyo-oka K, Yoshida N, Yamada M, Muramatsu M, Zhang D, Saya H, Toyoshima YY, Kinoshita K, et al: NDEL1 phosphorylation by Aurora-A kinase is essential for centrosomal maturation, separation, and TACC 3 recruitment. Mol Cell Biol 27: 352-367, 2007.

11. Di Fiore B, Ciciarello M and Lavia P: Mitotic functions of the Ran GTPase network: The importance of being in the right place at the right time. Cell Cycle 3: 305-313, 2004.

12. Bayliss R, Sardon T, Vernos I and Conti E: Structural basis of Aurora-A activation by TPX2 at the mitotic spindle. Mol Cell 12 851-862, 2003.

13. Wong J, Lerrigo R, Jang CY and Fang G: Aurora A regulates the activity of HURP by controlling the accessibility of its microtubule-binding domain. Mol Biol Cell 19: 2083-2091, 2008.
14. Santarella RA, Koffa MD, Tittmann P, Gross H and Hoenger A: HURP wraps microtubule ends with an additional tubulin sheet that has a novel conformation of tubulin. J Mol Biol 365: 1587-1595, 2007.

15. Yu CT, Hsu JM, Lee YC, Tsou AP, Chou CK and Huang CY: Phosphorylation and stabilization of HURP by Aurora-A: Implication of HURP as a transforming target of Aurora-A. Mol Cell Biol 25: 5789-5800, 2005.

16. Blangy A, Lane HA, d'Hérin P, Harper M, Kress M and Nigg EA: Phosphorylation by $\mathrm{p} 34 \mathrm{cdc} 2$ regulates spindle association of human Eg5, a kinesin-related motor essential for bipolar spindle formation in vivo. Cell 83: 1159-1169, 1995.

17. Ma N, Tulu US, Ferenz NP, Fagerstrom C, Wilde A and Wadsworth P: Poleward transport of TPX2 in the mammalian mitotic spindle requires dynein, Eg5, and microtubule flux. Mol Biol Cell 21: 979-988, 2010.

18. Cassimeris L and Morabito J: TOGp, the human homolog of XMAP215/Dis1, is required for centrosome integrity, spindle pole organization, and bipolar spindle assembly. Mol Biol Cell 15: 1580-1590, 2004.

19. Barr AR and Gergely F: MCAK-independent functions of ch-Tog/XMAP215 in microtubule plus-end dynamics. Mol Cell Biol 28: 7199-7211, 2008.

20. Koffa MD, Casanova CM, Santarella R, Köcher T, Wilm M and Mattaj IW: HURP is part of a Ran-dependent complex involved in spindle formation. Curr Biol 16: 743-754, 2006.

21. Chinn DC, Holland WS and Mack PC: Anticancer activity of the Aurora A kinase inhibitor MK-5108 in non-small-cell lung cancer (NSCLC) in vitro as monotherapy and in combination with chemotherapies. J Cancer Res Clin Oncol 140: 1137-1149, 2014.

22. Goldenson B and Crispino JD: The aurora kinases in cell cycle and leukemia. Oncogene 34: 537-545, 2015.

23. Melichar B, Adenis A, Lockhart AC, Bennouna J, Dees EC, Kayaleh O, Obermannova R, DeMichele A, Zatloukal P,Zhang B, et al: Safety and activity of alisertib, an investigational aurora kinase A inhibitor, in patients with breast cancer, small-cell lung cancer, non-small-cell lung cancer, head and neck squamous-cell carcinoma, and gastro-oesophageal adenocarcinoma: A five-arm phase 2 study. Lancet Oncol 16: 395-405, 2015.

24. Martens-de Kemp SR1, Nagel R, Stigter-van Walsum M, van der Meulen IH, van Beusechem VW, Braakhuis BJ and Brakenhoff RH: Functional genetic screens identify genes essential for tumor cell survival in head and neck and lung cancer. Clin Cancer Res 19: 1994-2003, 2013.

25. Beasley MB, Brambilla E and Travis WD: The 2004 World Health Organization classification of lung tumors. Semin Roentgenol 40: 90-97, 2005.

26. Wittekind C: 2010 TNM system: On the 7th edition of TNM classification of malignant tumors. Pathologe 31: 331-332, 2010 (In German).

27. Schneider MA, Granzow M, Warth A, Schnabel PA, Thomas M, Herth FJ, Dienemann H, Muley T and Meister M: Glycodelin: A new biomarker with immunomodulatory functions in non-small cell lung cancer. Clin Cancer Res 21: 3529-3540, 2015.

28. Bustin SA, Benes V, Garson JA, Hellemans J, Huggett J, Kubista M, Mueller R, Nolan T, Pfaffl MW, Shipley GL, et al: The MIQE guidelines: Minimum information for publication of quantitative real-time PCR experiments. Clin Chem 55: 611-622, 2009.

29. McShane LM, Altman DG, Sauerbrei W, Taube SE, Gion M and Clark GM; Statistics Subcommittee of the NCI-EORTC Working Group on Cancer Diagnostics: REporting recommendations for tumour MARKer prognostic studies (REMARK). Eur J Cancer 41: 1690-1696, 2005.

30. Dinse GE and Lagakos SW: Nonparametric estimation of lifetime and disease onset distributions from incomplete observations. Biometrics 38: 921-932, 1982.

31. Mann HB and Whitney DR: On a test whether one of two random variables is stochastically larger than the other. Ann Math Stat 18: 50-60, 1947.

32. Kruskal WH and Wallis WA: Use of ranks in one-criterion variance analysis. J Am Stat Assoc 47: 583-621, 1952.

33. Fieller EC, Hartley HO and Pearson ES: Tests for rank correlation coefficients I. Biometrika 44: 470-481, 1957.

34. Budczies J, Klauschen F, Sinn BV, Győrffy B, Schmitt WD, DarbEsfahani S and Denkert C: Cutoff Finder: A comprehensive and straightforward Web application enabling rapid biomarker cutoff optimization. PLoS One 7: e51862, 2012.

35. Fu J, Bian M, Xin G, Deng Z, Luo J, Guo X, Chen H, Wang Y, Jiang $Q$ and Zhang C: TPX2 phosphorylation maintains metaphase spindle length by regulating microtubule flux. J Cell Biol 210: 373-383, 2015 . 
36. Li Y, Tang H, Sun Z, Bungum AO, Edell ES, Lingle WL Stoddard SM, Zhang M, Jen J, Yang P, et al: Network-based approach identified cell cycle genes as predictor of overall survival in lung adenocarcinoma patients. Lung Cancer 80: 91-98, 2013.

37. Chen L, Zhuo D, Chen J and Yuan H: Screening feature genes of lung carcinoma with DNA microarray analysis. Int J Clin Exp Med 8: 12161-12171, 2015.

38. Eguchi T, Kadota K, Chaft J, Evans B, Kidd J, Tan KS, Dycoco J, Kolquist K, Davis T, Hamilton SA, et al: Cell cycle progression score is a marker for five-year lung cancer-specific mortality risk in patients with resected stage I lung adenocarcinoma. Oncotarget 7: 35241-35256, 2016.
39. Cuzick J, Swanson GP, Fisher G, Brothman AR, Berney DM, Reid JE, Mesher D, Speights VO, Stankiewicz E, Foster CS, et al; Transatlantic Prostate Group: Prognostic value of an RNA expression signature derived from cell cycle proliferation genes in patients with prostate cancer: A retrospective study. Lancet Oncol 12: 245-255, 2011.

40. Wistuba II, Behrens C, Lombardi F, Wagner S, Fujimoto J, Raso MG, Spaggiari L, Galetta D, Riley R, Hughes E, et al: Validation of a proliferation-based expression signature as prognostic marker in early stage lung adenocarcinoma. Clin Cancer Res 19: 6261-6271, 2013. 